\title{
Electrochemical Performance of Surfactant Assisted Hematite Nanoparticles by Chemical Synthesis Method
}

\author{
S. Ezhil Arasi, P. Devendran, A. Arivarasan
}

\begin{abstract}
Fe}_{2} \mathrm{O}_{3}$ nanoparticles were prepared by simple chemical route. The structural, functional, morphological properties of prepared nanoparticles were obtained by Powder $X$-ray Diffraction analysis, Fourier transform infrared spectroscopy, and Scanning Electron Microscopy analysis respectively. The average grain size of the prepared nanoparticles was calculated using the Scherrer formula. The functional groups and metal bonding were analyzed through FTIR analysis. The external morphology of the prepared nanomaterials was analyzed with scanning electron microscopy technique. Electrochemical property of the prepared nanomaterial was examined with the help of cyclic voltammetry, galvanostatic charge-discharge and electrochemical impedance spectroscopy.
\end{abstract}

Keywords: Hematite Nanoparticles, XRD, Electrochemical studies, Pseudocapacitor.

\section{INTRODUCTION}

A present promising candidate, alternative source of energy is the energy storage device like supercapaci-tors. The application of supercapacitors has been emerged by their low energy density [1]. There have been larger efforts spend on increasing the energy density by the researchers. And hence the research interest has been increased in maximizing the development of positive and negative electrode with higher specific capacitance [2], [3]. In past few decades, the role of transition metal oxides has been enormously increasing for their excellent optical and electrical properties which made it for utilizing in various applications such as energy storage devices, catalysis, photo-degradation etc., [4], [5]. The nano-particles with magnetic properties have attracted many researchers for their typical physical and chemical properties. By modifying the structure of nanoparticles, the properties and applications can be varied. Among various magnetic materials, hematite $\left(\mathrm{Fe}_{2} \mathrm{O}_{3}\right)$ nanoparticles has been widely synthesized and used in many applications [5], [6]. Also, it is an eco-friendly material that

Revised Manuscript Received on December 29, 2019.

* Correspondence Author

S. Ezhil Arasi, Department of Physics, Kalasalingam Academy of Research and Higher Education, Krishnankoil, Tamil Nadu 626126, India. Email: arasi1105@gmail.com

P. Devendran, Department of Physics, Kalasalingam Academy of Research and Higher Education, Krishnankoil, Tamil Nadu 626126, India. Email: pdevavenmani@gmail.com

A. Arivarasan*, Department of Physics, Kalasalingam Academy of Research and Higher Education, Krishnankoil, Tamil Nadu 626126, India. Email: arivarasan.nanotech@gmail.com is more stable and neutral in all alkaline solutions. Since the iron oxide nanomaterials possess excellent theoretical capacitance values, it can be used as an modified electrode material for a supercapacitor In general, the hematite nanoparticles can be pre-pared by various techniques such as combustion method, sol-gel technique [7], hydrothermal [8], etc., Of all these methods, simple chemical technique is the most common among many researchers as it is done in ordinary room temperature with mild conditions. Iron oxides exhibits variety of nanostructures [9]. Though various structures were available, the quasi spheres like structure exhibits better electrochemical behaviour. The iron oxide nanoparticles show excellent theoretical capacitance of about $382.7 \mathrm{mF} / \mathrm{cm}^{2}$ at $0.5 \mathrm{~mA} / \mathrm{cm}^{2}$ [10], [11]. In this study, the magnetic $\mathrm{Fe}_{2} \mathrm{O}_{3}$ nanoparticles were prepared through a cost-effective chemical method and characterized by PXRD, FTIR and SEM analysis from which the crystal structure, functional group analysis and surface morphology were examined. Electrochemical applications of the prepared surfactant assisted hematite nanoparticles were observed using the cyclic voltammetry, galvanostatic charge discharge, electro-chemical impedance spectroscopic studies [12].

\section{EXPERIMENTAL SECTION}

\section{A. Chemicals}

Analytical grade Iron (III) chloride hexa hydrate $\mathrm{Fe}(\mathrm{Cl})_{2} \cdot 6 \mathrm{H}_{2} \mathrm{O}$, was used as the precursors, polyvinylpyrolidine (PVP), sodium hydroxide $(\mathrm{NaOH})$ and ethanol were purchased from Sisco Research Laboratories Pvt. Ltd., Mumbai, India. All the chemicals with analytical grade was used as purchased. The entire reaction and electrolyte solutions were freshly prepared with deionized (DI) water. All the synthesis procedures were carried out in room temperature.

\section{B. Preparation of hematite nanoparticles}

Facile $\mathrm{Fe}_{2} \mathrm{O}_{3}$ nanoparticles was prepared using Iron (III) chloride hexa hydrate $\mathrm{Fe}(\mathrm{Cl})_{2} \cdot 6 \mathrm{H}_{2} \mathrm{O}$ as precursor material. Stoichiometric amount of $\mathrm{Fe}(\mathrm{Cl})_{2} \cdot 6 \mathrm{H}_{2} \mathrm{O}$ was dissolved in $100 \mathrm{ml}$ DI water. Aqueous solution of $\mathrm{NaOH}$ was added drop-wise in order to maintain the $\mathrm{pH}$ of reaction mixture at 7 . The reaction mechanism was given in equation (1).

$$
\begin{gathered}
2 \mathrm{Fe}(\mathrm{Cl})_{2} \cdot 6 \mathrm{H}_{2} \mathrm{O}+4 \mathrm{NaOH} \\
\rightarrow \mathrm{Fe}_{2} \mathrm{O}_{3}+4 \mathrm{NaCl}+10 \mathrm{H}_{2} \mathrm{O}(1) \\
\text { In addition, } 0.2 \mathrm{~g} \text { weight } \%
\end{gathered}
$$


of PVP was added in the resultant solution as surfactant and allowed to constant stir up to $1 \mathrm{~h}$.

The precipitate obtained was centrifuged many times with DI water and ethanol to remove the unwanted materials or additives present in the sample. Thus, the acquired precipitate was further air dried at ambient temperature then, calcinated at $300^{\circ} \mathrm{C}$ for $3 \mathrm{~h}$ to improve the crystallinity of sample.

\section{Characterizations and modified electrode fabrication}

The prepared hematite nanoparticles were characterized by powder X-ray diffraction analysis, Crystalline nature of prepared $\mathrm{Fe} 2 \mathrm{O} 3$ nanoparticles were confirmed by powder $\mathrm{X}$-ray diffraction analysis (PXRD) using Bruker X-ray diffractometer (D8 advance ECO) with monochromatic $\mathrm{Cu}-\mathrm{K} \alpha$ radiation $(\lambda=1.5406 \AA)$. Surface morphology of Fe2O3 nanoparticles was analyzed using ZEISS-EVO 18 Research, Japan, and Scanning Electron Microscope (SEM). sample Fourier transform infrared spectrometer (FTIR) was employed using a Shimadzu (IR Tracer-100) spectrophotometer within the range of $4000-400 \mathrm{~cm}^{-1}$ using $\mathrm{KBr}$ pellet system. Electrochemical analysis such as cyclic voltammetry, galvanostatic charge-discharge and electrochemical impedance spectroscopy were examined with the help of electrochemical workstation $(\mathrm{CH}$ instrument, CHI 6008e, USA). The workstation was three electrode system provided with $\mathrm{Ag} / \mathrm{AgCl}$ reference electrode, platinum wire as counter electrode and a modified electrode made of prepared nanomaterials. The electrolyte solution was made of aqueous solution of $1 \mathrm{M} \mathrm{KOH}$. The doctor blade technique was used to fabricate the modified electrode material.

\section{RESULTS AND DISCUSSION}

\section{A. X-Ray Diffraction analysis}

The crystalline structure of prepared PVP assisted $\mathrm{Fe}_{2} \mathrm{O}_{3}$ nanoparticles was examined by powder X-ray diffraction analysis. The PXRD pattern of prepared PVP assisted $\mathrm{Fe}_{2} \mathrm{O}_{3}$ nanoparticles were shown in Fig. 1. The range was fixed between $10-80^{\circ}$. The peaks were in good accordance with the bulk $\mathrm{Fe}_{2} \mathrm{O}_{3}$ (JCPDS card number \#898104) [13]. Eight different maximum peaks were observed in prepared PVP assisted $\mathrm{Fe}_{2} \mathrm{O}_{3}$ nanoparticles. The $2 \theta$ values and their corresponding hkl indices were $24.213^{\circ}$

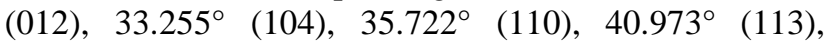
$49.602^{\circ}(024), 54.232^{\circ}(116), 62.615^{\circ}(214), 64.178^{\circ}$ (300) respectively. Broader peak suggests that the prepared sample were in nano size with rhombohedral crystal structure. The space group of prepared PVP assisted $\mathrm{Fe}_{2} \mathrm{O}_{3}$ nanoparticles was found to be $\mathrm{R} 3 \mathrm{c}(167)$ with cell parameters $a=5.023 \AA, c=13.708 \AA$. The grain size of prepared PVP assisted $\mathrm{Fe}_{2} \mathrm{O}_{3}$ nanoparticles were $\sim 12 \mathrm{~nm}$.

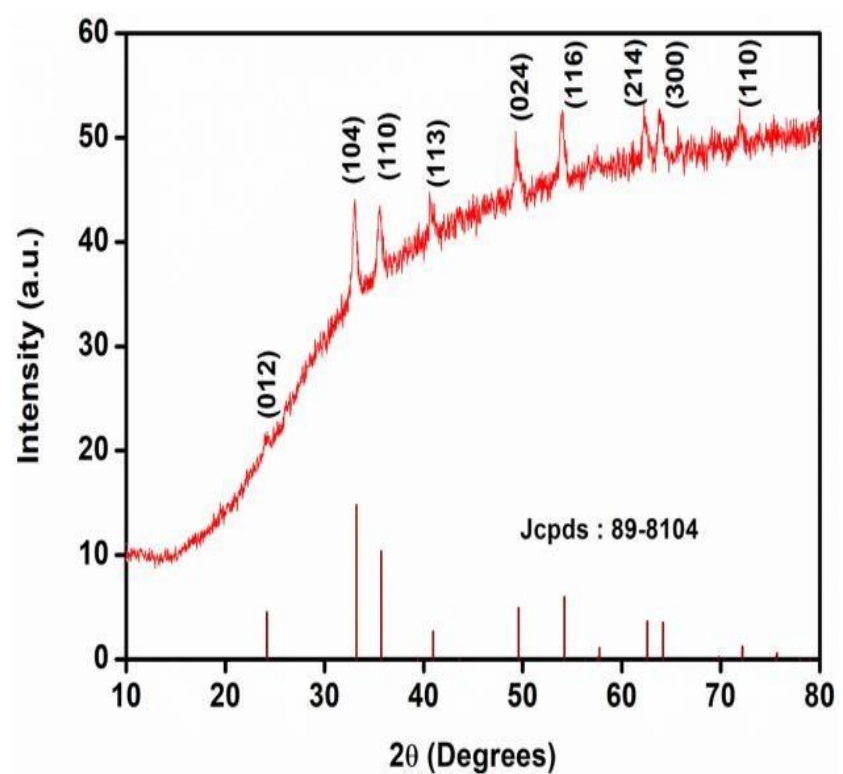

Fig. 1. XRD patterns of PVP assisted $\mathrm{Fe}_{2} \mathrm{O}_{3}$ nanoparticles

\section{B. Fourier Transform Infra-Red spectral analysis}

The functional groups and metal bonding were identified through the FTIR spectrum. Fig. 2. Shows the FTIR spectrum of the prepared hematite nanoparticles. Region between 800 to 400 was due to metal oxygen M-O lattice bonding vibrations. The vibrational modes of $\mathrm{Fe}-\mathrm{O}$ were confirmed through the emergence of peaks at 480 $\mathrm{cm}^{-}{ }^{1}, 540 \mathrm{~cm}^{-}{ }^{1}$. The peak at 590 and $786 \mathrm{~cm}^{-1}$ was due to the $\mathrm{Fe}-\mathrm{O}-\mathrm{Fe}$ bonding vibrations [14].

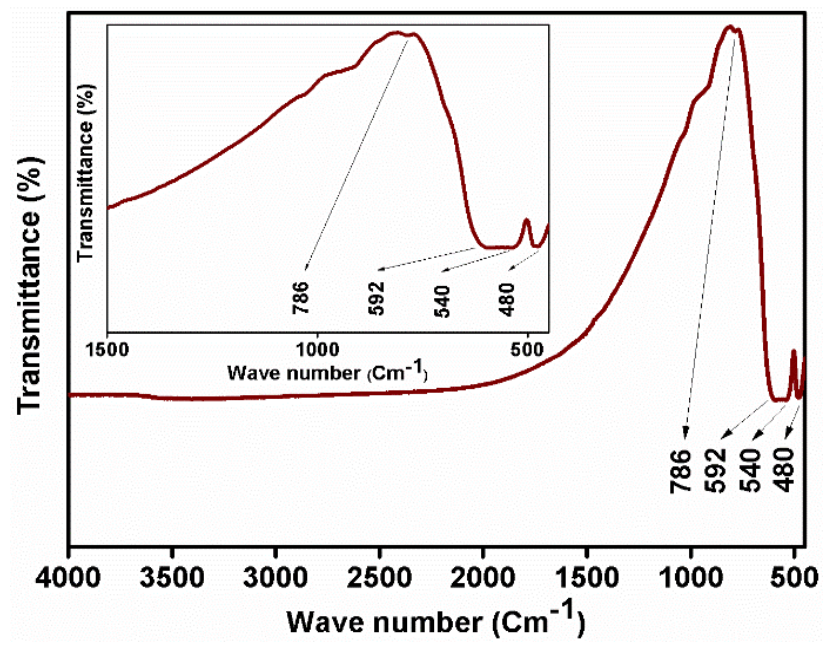

Fig. 2. FTIR spectrum of PVP assisted Fe2O3 nanoparticles

\section{Scanning Electron Microscopic studies}

Fig. 3 ( $\mathrm{a} \& \mathrm{~b}$ ) reveals the SEM images of PVP assisted $\mathrm{Fe}_{2} \mathrm{O}_{3}$ nanoparticles. The morphology of the $\mathrm{Fe}_{2} \mathrm{O}_{3}$ nanoparticles shows fine particles. The absence of agglomerate reveals the effect of surfactant molecules in the preparation procedure. The particle size was found to be 100-200 nm. SEM images also show the morphologies of agglomerated particles

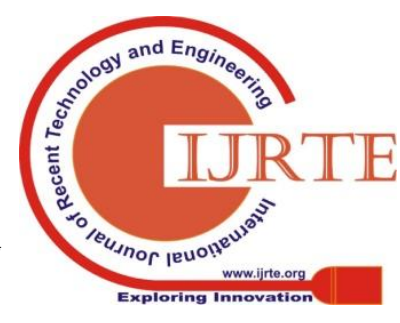


and surface of the nanocrystalline structures.

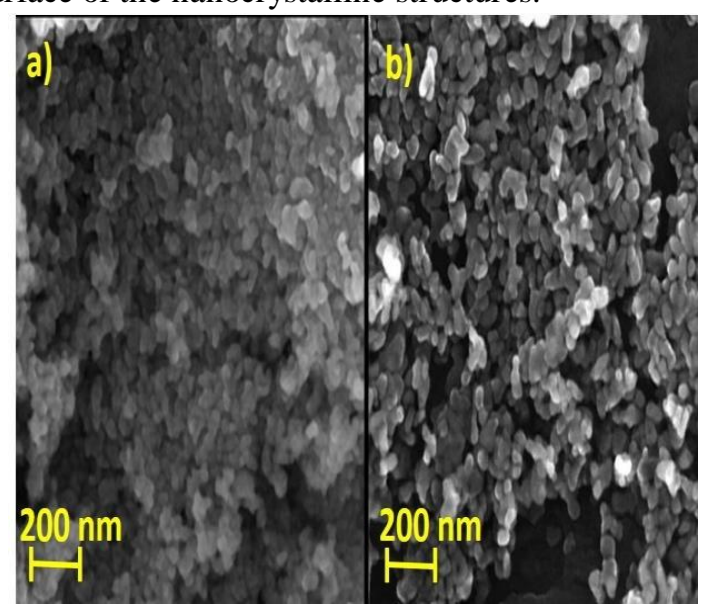

Fig. 3. SEM images of PVP assisted $\mathrm{Fe}_{2} \mathrm{O}_{3}$ nanoparticles

\section{Cyclic Voltammetry}

The supercapacitive performance were analyzed by $\mathrm{CV}$ curves in aqueous $1 \mathrm{M} \mathrm{KOH}$. CV curves of the surfactant assisted hematite nanoparticles were shown in Fig. 4. The potential window was fixed between 0 to 0.5 . Oxidation and reduction property of the prepared nanoparticles were analyzed through $\mathrm{CV}$ analysis. The $\mathrm{CV}$ curves were recorded for different scan rates from lower $5 \mathrm{mV} / \mathrm{s}$ to higher $100 \mathrm{mV} / \mathrm{s}$. The anodic and cathodic peak at $0.4 \mathrm{~V}$ reveals the pseudocapacitivie nature of the prepared material [8].

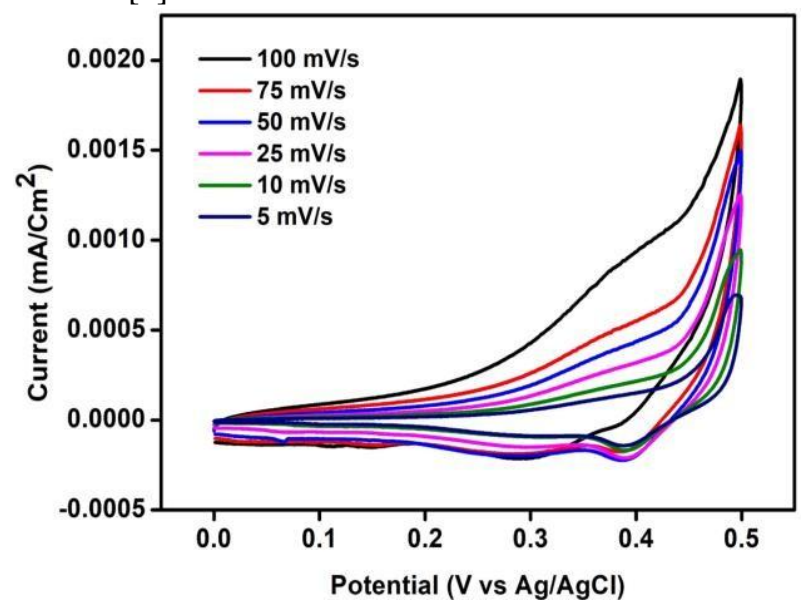

Fig. 4. CV curves of PVP assisted $\mathrm{Fe}_{2} \mathrm{O}_{3}$ nanoparticles

\section{E. Galvanostatic Charge-Discharge}

The charge storage and discharge mechanism of the prepared nanoparticles were analyzed through galvanostatic charge-discharge studies. Fig. 5. shows the GCD pattern of prepared surfactant assisted hematite nanoparticles. The current density applied ranges from lower 0.2 to $0.5 \mathrm{~mA} / \mathrm{cm}^{2}$. For very low input current the discharge is maximum as the ion transfer was very slower between the electrode and electrolyte.

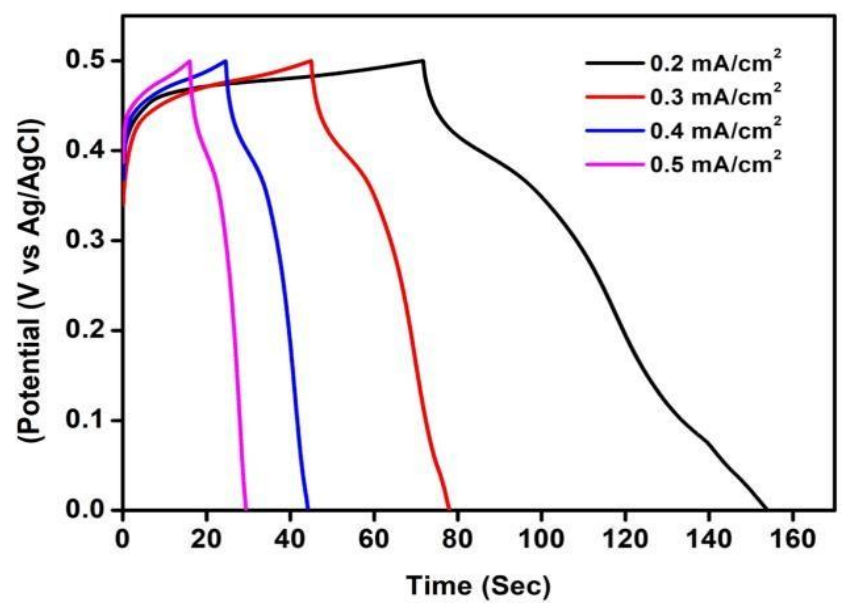

Fig. 5. GCD patterns of PVP assisted $\mathrm{Fe}_{2} \mathrm{O}_{3}$ nanoparticles

\section{F. Electrochemical Impedance Spectroscopy}

The impedance, conductivity and movement of ions of the prepared surfactant assisted hematite nanoparticles were studied by electrochemical impedance spectroscopy. Fig. 6. shows the nyquist plot for the prepared nanomaterial. The frequency regions define the material supercapacitive behavior. At higher frequency region the semicircle forms which was due to the bulk resistance of the nanomaterial and at lower frequency region diffusion process takes place between ion in electrode/electrolyte interface. The small semi-circle at the beginning of the curve was due to charge transfer resistance. The slope line at almost $45^{\circ}$ perfectly clarifies that the prepared material has supercapacitive performance.

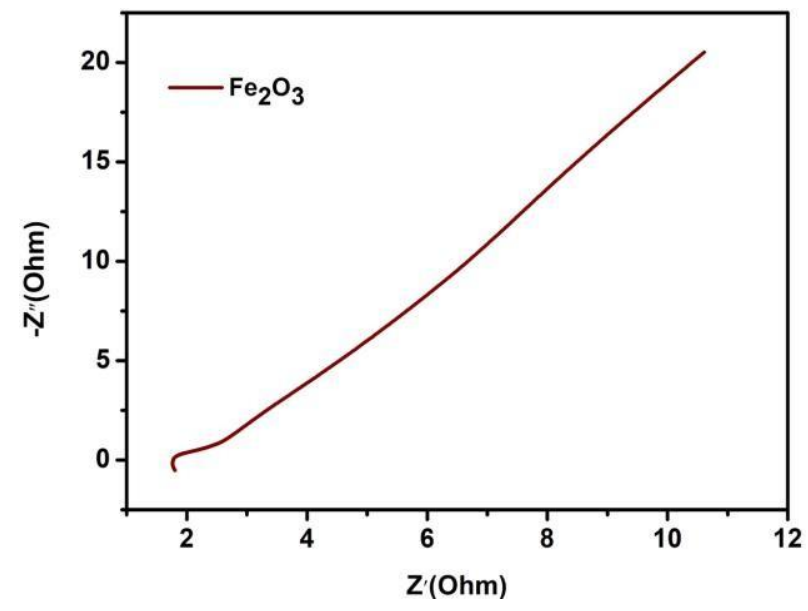

Fig. 6. EIS analysis of PVP assisted Fe2O3 nanoparticles

\section{CONCLUSION}

Iron oxide nanoparticles were prepared by chemical route. The crystallite size of the prepared nanoparticles was found to be $\sim 12 \mathrm{~nm}$. The XRD studies revealed that that the prepared nanoparticles have the rhombohedral structure. The SEM analyses showed that the prepared nanomaterials were in $200 \mathrm{~nm}$ range. 
The electrochemical studies for energy storage applications revealed that the material has good redox property with excellent charge-discharge capability and also exhibits good conducting nature. Finally, it was confirmed through all the studies that the material can be used as an electrode for electrochemical storage applications.

\section{ACKNOWLEDGMENT}

The authors show their gratitude to IRC, Kalasalingam Academy of Research and Education (KARE) for providing research facilities and owe thankful for funding under the University Research Fellowship (URF) scheme.

\section{REFERENCES}

1. A. González, E. Goikolea, J. A. Barrena, and R. Mysyk, "Review on supercapacitors: Technologies and materials," Renew. Sustain. Energy Rev., vol. 58, pp. 1189-1206, 2016.

2. X. Zhao, B. M. Sánchez, P. J. Dobson, and P. S. Grant, "The role of nanomaterials in redox-based supercapacitors for next generation energy storage devices," Nanoscale, vol. 3, no. 3, pp. 839-855, 2011.

3. Y.-W. Yang, T. Wang, D. Wang, J. Guo, Y. Wang, and J. Shao, "Mesoporous Transition Metal Oxides for Supercapacitors,' Nanomaterials, vol. 5, no. 4, pp. 1667-1689, 2015.

4. E. A. Campos, D. V. B. S. Pinto, J. I. S. de Oliveira, E. da C. Mattos, and R. de C. L. Dutra, "Synthesis, characterization and applications of iron oxide nanoparticles - A short review," J. Aerosp. Technol. Manag., vol. 7, no. 3, pp. 267-276, 2015.

5. Y. S. Kang, S. Risbud, J. F. Rabolt, and P. Stroeve, "Synthesis and Characterization of Nanometer-Size Fe 3 O 4 and $\gamma$-Fe 2 O 3 Particles," Chem. Mater., vol. 8, no. 9, pp. 2209-2211, 1996.

6. Q. Ma et al., "Persulfate activation by magnetic $\Gamma-\mathrm{Fe} 2 \mathrm{O} 3 / \mathrm{Mn} 3 \mathrm{O} 4$ nanocomposites for degradation of organic pollutants," Sep. Purif. Technol., vol. 210, pp. 335-342, 2019.

7. K. Woo, H. J. Lee, J. P. Ahn, and Y. S. Park, "Sol-Gel Mediated Synthesis of Fe2O3 Nanorods," Adv. Mater., vol. 15, no. 20, pp. 1761-1764, 2003.

8. Z. Ma, X. Huang, S. Dou, J. Wu, and S. Wang, "One-pot synthesis of $\mathrm{Fe} 2 \mathrm{O} 3$ nanoparticles on nitrogen-doped graphene as advanced supercapacitor electrode materials," J. Phys. Chem. C, vol. 118, no. 31, pp. 17231-17239, 2014.

9. F. Yang, K. Xu, and J. Hu, "Construction of Co3O4@Fe2O3 core-shell nanowire arrays electrode for supercapacitors," J. Alloys Compd., vol. 729, pp. 1172-1176, 2017.

10. S. Yin et al., "Synergistic contributions by decreasing overpotential and enhancing charge-transfer in $\alpha$-Fe2O3 /Mn3O4 /graphene catalysts with heterostructures for photocatalytic water oxidation," Phys. Chem. Chem. Phys., vol. 16, no. 23, pp. 11289-11296, 2014.

11. Y. Liu, L. Yu, Y. Hu, C. Guo, F. Zhang, and X. Wen Lou, "A magnetically separable photocatalyst based on nest-like $\gamma$-Fe2O3/ZnO double-shelled hollow structures with enhanced photocatalytic activity," Nanoscale, vol. 4, no. 1, pp. 183-187, 2012.

12. B. Koo et al., "Hollow iron oxide nanoparticles for application in lithium ion batteries," Nano Lett., vol. 12, no. 5, pp. 2429-2435, 2012.

13. N. Boda et al., "Effect of rare earth elements on low temperature magnetic properties of $\mathrm{Ni}$ and Co-ferrite nanoparticles," J. Magn. Magn. Mater., vol. 473, pp. 228-235, 2019.

14. A. Abdelkader et al., "Steam reforming of ethanol over $\mathrm{Co} 3 \mathrm{O} 4$ e Fe2O3 mixed oxides," Int. J. Hydrogen Energy, vol. 38, no. 20, pp. 8263-8275, 2013.

\section{AUTHORS PROFILE}

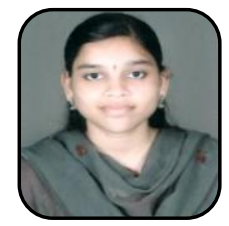

Ms. S. Ezhil Arasi born on 1994 in Erode, Tamilnadu. She obtained her Master degree in Physics in 2017 at Bharathiar University, Coimbatore. She joined $\mathrm{PhD}$ in 2017 under the supervision of Dr. A. Arivarasan at Kalasalingam Academy of Research and Education in Virudhunagar district. Her research interest is focused on the area of nanomaterials and carbon-based binary metal nanocomposites synthesis for energy storage device fabrication application.
Dr. P. Devendran received his Ph.D degree in Physics from Madras University at Chennai in 2016, developing metal oxides and metal sulfide nano-catalysts

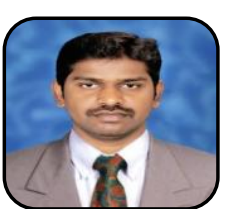
for photocatalytic application. After he moved for postdoctoral studies at IRC, Kalasalingam academy of Research and education, he becomes an Assistant Professor of Physics at the same institution and presently began studying metal oxide modified graphene-based materials for energy storage device application and their surface science. He published more than 28 research articles and book chapters in reputed journals.

Dr. A. Arivarasan is currently working as Assistant Professor at Kalasalingam academy of Research and education, Virudhunagar, India. He completed his MSc (Physics) degree in Bharathidasan University, Trichy. He received both his M.Tech. (Nanotechnology) and Ph.D

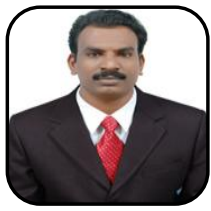
(Nanotechnology) degrees from Anna University in the years of 2010 and 2014, respectively on Quantum Dots for Solar Cell Applications. He has published nearly 10 publications in peer reviewed international journals and more than 25 conference proceedings. His current research interests are in the fields of supercapacitor electrodes, redox electrolytes and device fabrications. 